American Journal of Pharmaceutical Education 2020; 84 (11) Article 8241.

\title{
REVIEW
}

\section{A Scoping Review of Active-Learning Strategies for Teaching Social Determinants of Health in Pharmacy}

\author{
Tyler Kiles, PharmD, Hilary Jasmin, MSIS, Brittany Nichols, PharmD, Romena Haddad, \\ Chelsea P. Renfro, PharmD \\ University of Tennessee Health Science Center, College of Pharmacy, Memphis, Tennessee \\ Submitted June 16, 2020; accepted August 12, 2020; published November 2020.
}

\begin{abstract}
Objective. To review current conceptualizations and measurements of active-learning education within Doctor of Pharmacy degree programs as it pertains to social determinants of health (SDOH) and to determine the gaps and limitations in available literature. A secondary objective was to assess simulation-based educational methods related to SDOH in pharmacy.

Findings. Sixteen articles were eligible for inclusion. Many simulation-based and non-simulationbased teaching strategies are described. The majority of articles included active-learning activities related to social/community context and health/health care, the other three 3 social determinants of health domains: education, economic stability, and neighborhood/built community, were not equally addressed. In the studies included in this review, schools and colleges of pharmacy did not appear to not be integrating all five components of SDOH into active learning curricula. The sparsity of literature and lack of diversity in published types of simulated experiences and assessments may suggest there is room for innovation in this area.
\end{abstract}

Summary. More research is needed in order to fully characterize conceptualizations of social determinants of health in Doctor of Pharmacy degree programs in order to ensure students are provided with a full understanding of the SDOH factors that affect patient outcomes.

Keywords: simulation, active learning, social determinants

\section{INTRODUCTION}

Expenditure for health care services in the United States increased to 3.65 trillion dollars in $2018 .^{1,2}$ The United States spends more capital on health care than any other developed country but produces dramatically poorer health outcomes, including lower life expectancy, higher infant mortality, and higher chronic disease burden. ${ }^{3,4}$ Despite the US allocating nearly $20 \%$ of its gross domestic product (GDP) for medical care spending, overall health is governed by a myriad of external factors. ${ }^{3}$ Behavioral factors account for about $30 \%$ of health outcomes and clinical care comprises approximately $20 \%$, while social/economic factors and physical environment determine an estimated $50 \%$ of health outcomes. ${ }^{5}$ Defined by the World Health Organization, the term social determinants of health $(\mathrm{SDOH})$ refers to "the subset of inherited conditions in which people are expected to live, grow, work and age." "6 The Healthy People 2020 campaign, led by the Office of Disease Prevention

Corresponding Author: Chelsea P. Renfro, University of Tennessee Health Science Center, College of Pharmacy, 881 Madison Ave., Memphis, TN 38163. Tel: 901-448-3514.

Email: crenfro@uthsc.edu and Health Promotion, categorizes SDOH into five key domains: social and community context, education, neighborhood and built environment, health and health care, and economic stability. ${ }^{7}$ Examples within these categories can be seen in Figure 1. To provide the best clinical care, health professionals must be able to understand the totality of a patient's circumstance and bridge clinical knowledge with social considerations. Neglecting these social factors limits the efficacy of clinical interventions. Thus, proper training to recognize and address SDOH is necessary for all members of the patient care team.

Pharmacists in various settings are recognized as valuable members of the health care team, helping to improve patient education, medication adherence, and medication therapy management. Pharmacists will inevitably interact with patients presenting with external factors that limit or prohibit adherence to clinical recommendations. In order to develop practical, patientcentered solutions to ensure optimal health outcomes, pharmacists need to understand the individual and societal factors that shape patients' access to medications and capacity to adhere to instructions. 


\section{American Journal of Pharmaceutical Education 2020; 84 (11) Article 8241.}

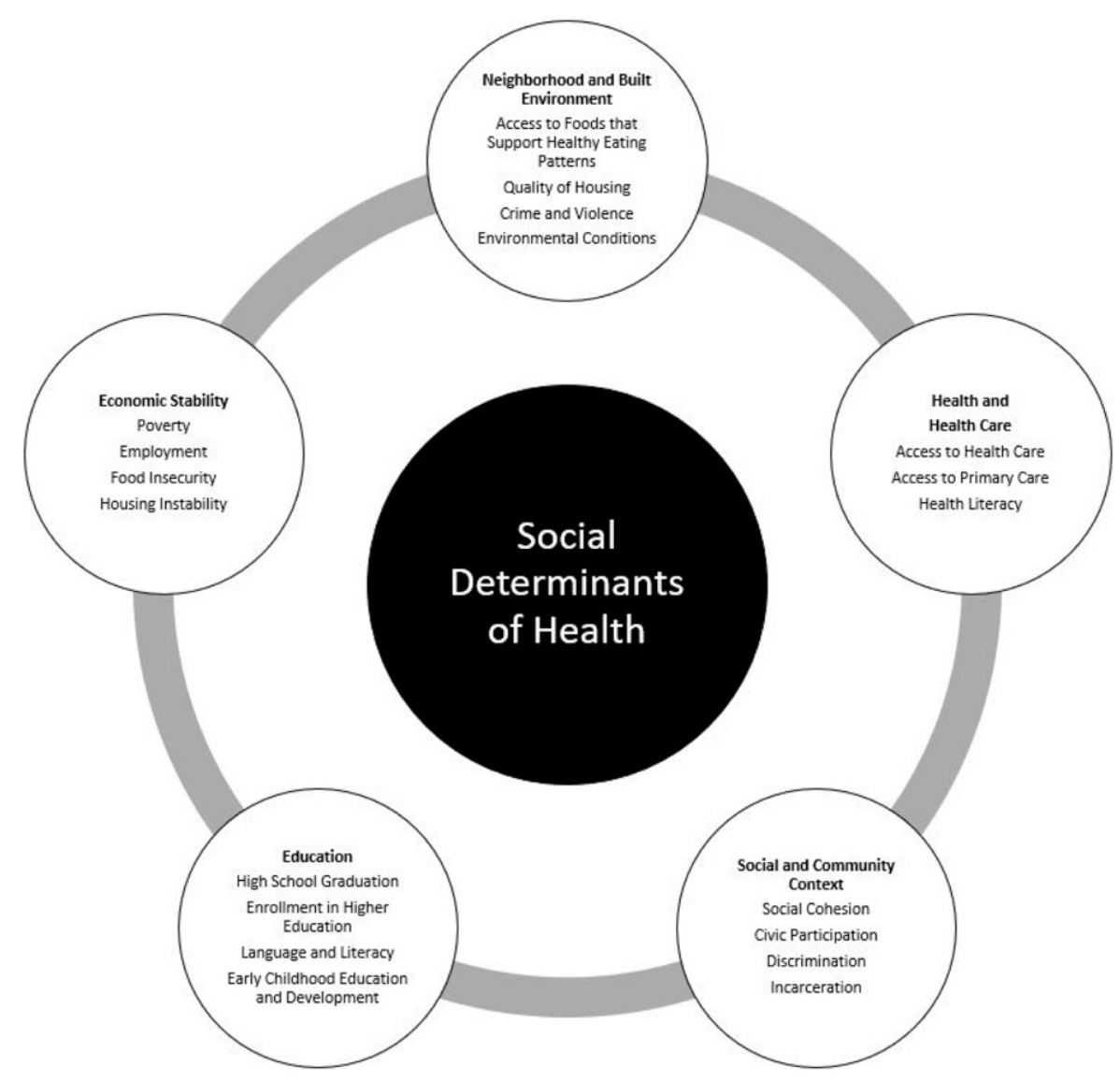

Figure 1. The Social Determinants of Health

Literature regarding $\mathrm{SDOH}$ pedagogy has been reviewed in medical and nursing professions. ${ }^{8-13}$ However, educational strategies for teaching SDOH within Doctor of Pharmacy (PharmD) programs are currently undefined. The Center for Advancement of Pharmacy Education (CAPE 2013) emphasizes the importance of social determinants of health, and SDOH is also referenced in Standard 3.5 of the 2016 Accreditation Council for Pharmacy Education (ACPE) Standards. ${ }^{14,15}$ Schools and colleges of pharmacy have been charged with integrating SDOH principles into the curricula.

While traditional lecture may be used to teach about $\mathrm{SDOH}$, the landscape of pharmacy education has evolved from passive, lecture-based instruction to curricula focused on active-learning to improve student engagement in learning. ${ }^{16,17}$ Active-learning strategies may include discussion-based learning, problem-based learning, casebased learning, team-based learning, and simulationbased learning, among many others. ${ }^{17}$ While these methods may be successful along the continuum for learning, of the listed pedagogies, simulation-based education may be the most promising strategy to teach pharmacy students about the social determinants of health. Simulation-based education, as defined by the Society for Simulation in Healthcare ( $\mathrm{SSH}$ ), serves as "a bridge between classroom learning and real-life clinical experience." 18 Simulation can enhance communication, improve empathy, and develop proficiency in practical skills. High-fidelity interactions with standardized patients and carefully engineered systems expose students to basic practical and interpersonal skills. The practice of simulation increases student engagement and may increase retention compared to lecture-based learning alone. ${ }^{19,20}$ Through simulation, learners communicate and perform clinical skills in a low-stakes environment. This incentive allows the learner to make the wrong decision, critically reflect on their cognitive process, and readdress the situation without the anxiety of high-stakes reform. ${ }^{21}$ Simulation-based pharmacy education is often used to teach and assess skills such as conducting a medication history interview or counseling a patient, but it can also be used to enhance student understanding of access to health care, availability of food, literacy, and culture. While SDOH principles may be conveyed conceptually through lecture-based instruction, activelearning strategies, including simulation, bring these 


\section{American Journal of Pharmaceutical Education 2020; 84 (11) Article 8241.}

social constructs to life in a way that engages students in understanding and impacting patient care.

The objective of this scoping review is to describe current conceptualizations and measurements of active-learning education within Doctor of Pharmacy degree programs as it pertains to $\mathrm{SDOH}$ and to determine the gaps and limitations in available literature. A secondary objective was to assess simulation-based educational methods related to $\mathrm{SDOH}$ in pharmacy.

\section{METHODS}

The aim of a scoping review is to examine an existing body of literature on a given topic in order to determine gaps, map concepts, and establish routes for future research. This methodology does not employ the analysis of included articles for the purpose of recommending best practices; rather, it works as a conceptual map of the topic and its range across scholarship. Following the Arksey and O'Malley framework, this scoping review was undertaken to identify studies that reported methods of instruction about the social determinants of health $(\mathrm{SDOH})$ in pharmacy curricula, with a particular interest in studies that used simulation. ${ }^{22}$ This review was conducted in compliance with the Preferred Reporting Items for Systematic reviews and Meta-Analyses extension for Scoping Reviews (PRISMA-ScR).

Four electronic databases (PubMed, CINAHL, Scopus, and Web of Science) were searched using a combination of keywords, Medical Subject Headings (MeSH), and/or CINAHL subject headings. Because of the limited amount of literature available on the $\mathrm{SDOH}$, the grey literature (eg, conference proceedings, regulatory data, etc) was not searched. Upon initial search building, the use of terms around simulation and activelearning yielded insufficient results. As the search strategy did not allow for such specificity, final search concepts included curriculum, pharmacy education, and SDOH (Appendix 1).

One hundred forty-eight results were imported into EndNote, version 9 (Clarivate, Philadelphia, PA), then duplicate records were removed, leaving a total of 75 articles. The unique records were imported into Rayyan QCRI (Qatar Computing Research Institute, Doha, Qatar), an online platform designed to expedite screening. Blinded screening was undertaken by three reviewers. Studies were included if they reported on curricular activities in pharmacy education that focused on SDOH, particularly those that involved active learning. Studies that involved interprofessional education were included if pharmacy was one of the disciplines included. No limits were set on the language, publication date range, or country of origin of an article. All study designs were eligible. Studies were excluded if they did not focus on curricular methods of teaching the social determinants of health to pharmacy students. Studies lacking a description of active learning or simulation, were excluded. The screening in the abstract phase excluded 55 results, leaving 20 studies for full-text screening to determine their eligibility for inclusion in the review (Figure 2). In screening the full-text articles, three did not meet criteria and were excluded. One more study was excluded during data extraction upon learning that the study described a certification program rather than a curricular intervention in a course. This left 16 articles that qualified for inclusion in the review.

Each of the included studies and the activities described in them were reviewed in detail by the research team. The active-learning activities described in each paper were tagged as being either simulation-based or non-simulation-based and also categorized with the appropriate SDOH Domain(s) as defined by Healthy People 2020. Tagging to SDOH domains was accomplished through prospective discussion of parameters among the reviewers and was based on reconciliation of the activity description with the descriptions of the SDOH domains. For example, for the purposes of this study, cultural competency activities were categorized under both social/ community context and health/health care, while an activity specifically about health care for the homeless would be characterized under economic stability, neighborhood/built environment, and health/health care (Figure 1). While there may be conceptual overlap among the SDOH domains (ie, education can affect many aspects), the authors tagged studies based on the specific objectives of the activities described.

\section{RESULTS}

The 16 identified studies varied in how they were conducted and in their outcomes. Many of the studies $(\mathrm{n}=7,44 \%)$ described more than one educational technique used to teach about the social determinants of health (SDOH). The active-learning techniques described included: simulation $(n=10)$, group discussion $(n=9)$, patient case videos $(n=8)$, self-reflection exercises $(n=6)$, analysis of patient education materials $(n=2)$, service learning $(n=2)$, team-based learning $(n=1)$, photographic essay $(n=1)$, and book club $(n=1)$.

The non-simulation-based, active-learning strategies are described in Table 1. Simulation-based strategies are described in Table 2. All activities described were part of required (rather than elective) coursework. The curricular placement of the activities varied; some studies described activities during the first professional year 


\section{American Journal of Pharmaceutical Education 2020; 84 (11) Article 8241.}

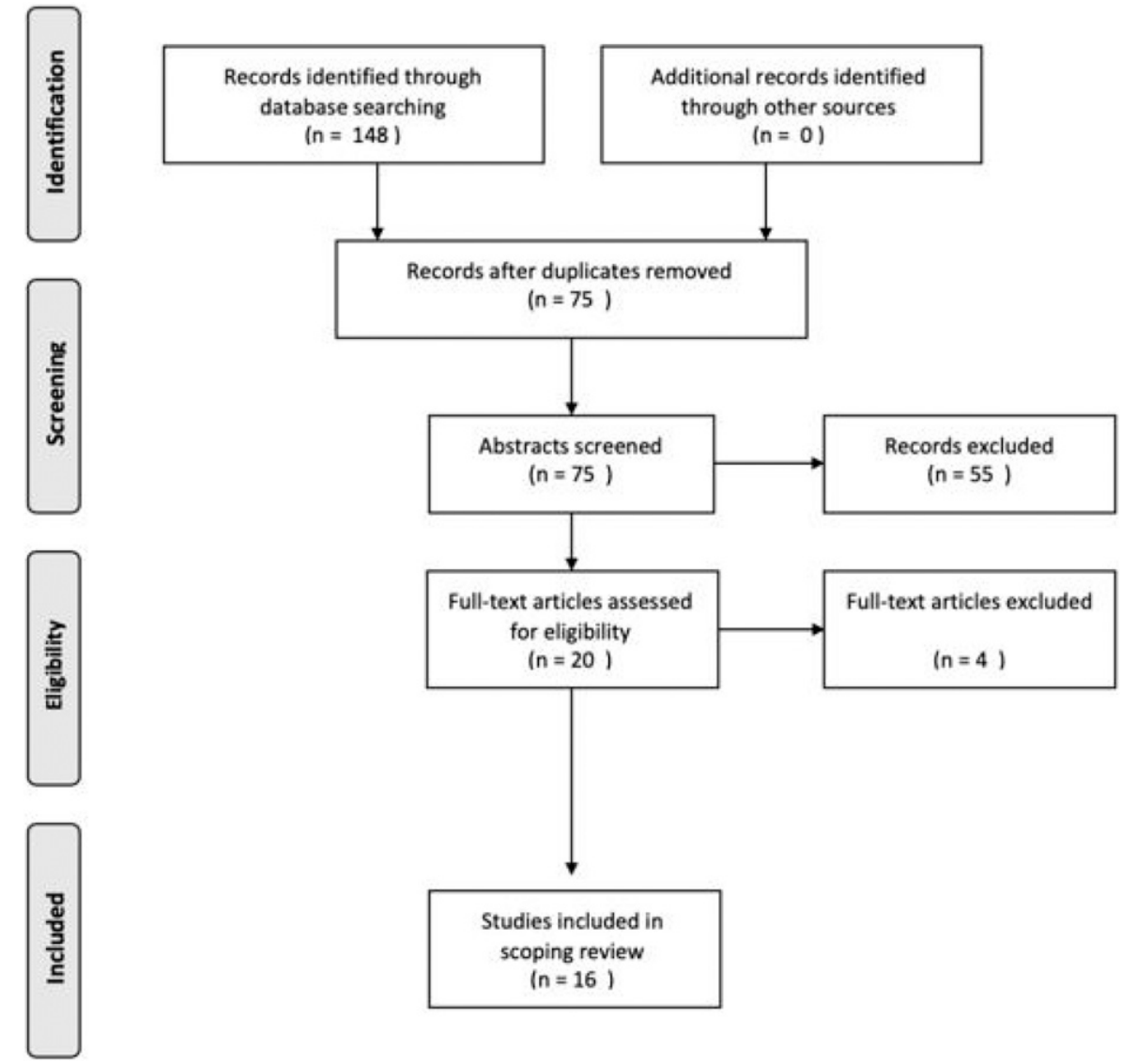

Figure 2. Adapted PRISMA Flow Diagram (2009)

$(\mathrm{n}=6)$, second professional year $(\mathrm{n}=5)$, and third professional year $(n=3)$, while others incorporated active learning longitudinally throughout multiple semesters of the didactic curricula $(n=3)$. The majority of studies included only PharmD students; however, two studies described interprofessional active-learning exercises related to SDOH that involved nursing students.

The most common form of assessment in the included studies was a pre/post-intervention survey $(n=11$, 69\%). Three studies employed a version of the Inventory for Assessing the Process of Cultural Competence among Healthcare Professionals (IAPCC) and two studies used the Clinical Cultural Competency Questionnaire (CCCQ). Other methods of assessment included other survey instruments $(n=10)$, course evaluations $(n=2)$, qualitative analysis $(n=2)$, peer evaluation $(n=1)$, multiple-choice questions in a quiz $(\mathrm{n}=1)$, and readiness assessment tests (RATs) $(n=1)$.

The instructional activities included in this study targeted the five key social determinants of health ${ }^{7}$ with the following overall distribution (Table 3 ): health/health care and social/community context were the most commonly examined topics $(94 \%$ and $88 \%$ of activities, respectively), followed by education and economic stability (56\% each) and neighborhood/built environment $(50 \%)$.

\section{Simulation-Specific Results}

Of the 10 simulation-based activities identified in the literature related to $\mathrm{SDOH}$, the most common method employed was a simulated patient encounter (such as mock counseling or role play) with peers $(80 \%)$. One study by Clarke and colleagues ${ }^{35}$ used poverty simulation, and another used a cultural simulation game (Westberg and colleagues ${ }^{33}$ ). None of the simulation activities described were interdisciplinary. A study by Prescott and colleagues included the use of a standardized patient. ${ }^{31}$ With the exception of two studies (Clarke and colleagues and Devraj and colleagues), the other simulation activities described were specifically intended to foster cultural competence. The study by Clarke ${ }^{35}$ and colleagues was designed to address student attitudes towards poverty, and the project by Devraj and colleagues ${ }^{26}$ was intended to develop students' knowledge and confidence related to patients with low health literacy. 


\section{American Journal of Pharmaceutical Education 2020; 84 (11) Article 8241.}

Table 1. Non-Simulation-Based Active-Learning Activities Described in Articles Included in a Scoping Review of ActiveLearning Strategies for Teaching Social Determinants of Health to PharmD Students

\begin{tabular}{|c|c|}
\hline$\overline{\operatorname{Arif}(2017)^{23}}$ & $\begin{array}{l}\text { Two-hour active learning workshop, which included self-awareness questionnaire titled "How } \\
\text { do you relate to various groups of people in the society?" and simulated patient case videos } \\
\text { with group discussion. }\end{array}$ \\
\hline Baverstock $(2018)^{24}$ & $\begin{array}{l}\text { Photography essay contest in which students were required to take a photograph in their local } \\
\text { environment that demonstrated social, cultural, or environmental determinants of health. }\end{array}$ \\
\hline Cailor $(2015)^{25}$ & $\begin{array}{l}\text { Created pill cards. Used "think-pair-share" to discuss incorporating patients' personal beliefs } \\
\text { into care recommendations. Rewrote patient education sheets to 5th grade reading level. }\end{array}$ \\
\hline Devraj $(2010)^{26}$ & $\begin{array}{l}\text { Practiced administering health literacy assessments and identifying formal signs of low health } \\
\text { literacy. Rated readability of drug information, analyzed information in drug advertisements, } \\
\text { and wrote patient education materials. }\end{array}$ \\
\hline Haack $(2012)^{27}$ & $\begin{array}{l}\text { Used Worlds Apart video series to curate group discussions. Self-reflections through a drawing } \\
\text { exercise. Created group presentations on cultural healthcare dilemmas. }\end{array}$ \\
\hline Liu $(2015)^{28}$ & $\begin{array}{l}\text { Used Beyond the Vital Signs video and Worlds Apart video series to curate group discussions. } \\
\text { Used team-based learning to discuss patient case scenarios. }\end{array}$ \\
\hline Muzumdar $(2010)^{29}$ & A series of videos was used to curate group discussion and self-reflection. \\
\hline Poirier $(2009)^{30}$ & $\begin{array}{l}\text { Use of If These Walls Could Talk video to create group discussion and self-reflection. Team } \\
\text { project and presentation on an assigned minority group. }\end{array}$ \\
\hline Prescott $(2019)^{31}$ & $\begin{array}{l}\text { Global Bead activity to create reflection around one's own cultural awareness. Trading Places } \\
\text { exercise to identify personal biases. Worlds Apart video and discussion. }\end{array}$ \\
\hline Vyas $(2010)^{32}$ & $\begin{array}{l}\text { Videos and discussions around religious and socioeconomic factors to consider when giving } \\
\text { care. Students gave 15-minute presentations on various health disparities. }\end{array}$ \\
\hline Westberg $(2005)^{33}$ & $\begin{array}{l}\text { Cultural competency book club, using "The Spirit Catches You and You Fall Down." Worlds } \\
\text { Apart video and discussion. Other activities included group discussions on patient sensitivity } \\
\text { and explanatory models. }\end{array}$ \\
\hline
\end{tabular}

Many of the studies used more than one educational technique to teach students about the SDOH and assessment of simulation-specific activities was not delineated from the overall course assessment. However, for the singular simulations described, pre-post activity surveys were used. A few of these studies also described providing peer and/or faculty feedback.

\section{DISCUSSION}

This review assessed available publications to determine the current conceptualizations and measurements of active-learning education within Doctor of Pharmacy degree programs as it pertains to the social determinants of health and to determine the gaps and limitations in the literature. The majority of the included articles reference a social or community context and health or health care, but the other three SDOH domains, ie, education, economic stability, and neighborhood/built environment, were not equally addressed in the literature. While many activities covered multiple aspects of $\mathrm{SDOH}$, in the studies identified by this review, active-learning exercises were largely used to train students for compassionate and culturally competent patient-centered interactions. While cultural competency and $\mathrm{SDOH}$ overlap, there is a complex interplay between these concepts. Cultural competence, the ability to understand, communicate with, and effectively interact with people across cultures, is a cornerstone of communication and patient care, and is an integral component of $\mathrm{SDOH}$; however, the terms should not be used interchangeably. ${ }^{39}$ The Accreditation Council for Pharmacy Education (ACPE) Standards 2007 included cultural diversity, but were updated to include the addition of SDOH in $2016 .^{40,15}$ The social determinants of health may be influenced by culture but encompass much more than interpersonal differences in cultural practices or worldviews. For example, a patient with low health literacy might not be able to comprehend a pharmacy leaflet. Likewise, patients with limited access to transportation may not be aware of prescription delivery options. Patients without housing may not have proper storage for medications that need to be refrigerated (eg, insulin) or secured (eg, opioids). Being culturally aware in these interactions is not enough to affect health outcomes influenced by these other SDOH constructs. It is important for Doctor of Pharmacy degree programs to incorporate all SDOH domains into the curriculum. It should not assume that including cultural awareness training in the curriculum fully addresses SDOH.

The educational interventions captured in this study largely focused on the $\mathrm{SDOH}$ at an individual level, but 


\section{American Journal of Pharmaceutical Education 2020; 84 (11) Article 8241.}

Table 2. Simulation-Based Active-Learning Activities Described in Articles Included in a Scoping Review of Active-Learning Strategies for Teaching the Social Determinants of Health to Doctor of Pharmacy Students

\begin{tabular}{ll}
\hline Assemi $(2004)^{34}$ & $\begin{array}{c}\text { Students role-played patient counseling in small groups, followed by discussion. } \\
\text { Cailor }(2015)^{25}\end{array}$ \\
$\begin{array}{c}\text { Students practiced the Teach-Back Method for counseling in small groups while receiving peer } \\
\text { and instructor feedback. } \\
\text { Clarke }(2016)^{35}\end{array}$ \\
$\begin{array}{l}\text { Students participated in the Missouri Association for Community Action Poverty Simulation. } \\
\text { Okevraj }(2010)^{26}\end{array}$ \\
$\begin{array}{l}\text { Students conducted mock patient counseling sessions to practice clear communication. } \\
\text { Students participated in a medication history role-playing lab involving cross-cultural } \\
\text { encounters. } \\
\text { Prescott }(2019)^{31}\end{array}$ \\
Students mock-counseled patients on new prescriptions while navigating cross-cultural \\
differences.
\end{tabular}

may not fully provide students with an understanding of the upstream social factors, ie, the governmental and economic policies that contribute to inequity in health outcomes. While active-learning may be an effective educational strategy to provide students with practical interpersonal skills, it may also be used to impart and assess a true understanding of population health, health disparities, and historical context for the social determinants of health. These social issues in all SDOH domains must be considered with a socioecological approach, taking into account the multiple-level factors of influence: individual, interpersonal, community, and societal. ${ }^{41}$ Diaz-Cruz calls for a paradigm shift from awareness to action and advocacy. ${ }^{42}$ For example, cultural awareness can impact social interactions, however, cultural competence can also influence other domains of the socioecological model. For example, failure to understand the culture of a community may lead to ineffective policies and community interventions. The list of social challenges faced by patients navigating the health care system in the United States is extensive. Also, health care providers being aware of the SDOH does not necessarily translate to them taking appropriate action to address these concerns. ${ }^{43}$ More research is needed to analyze how students are being trained to effectively advocate for patients who may be negatively impacted by the SDOH.

The social determinants of health may also be impacted by regionality, and social challenges may differ when assessed on a global, national, regional, or local scale. For example, this review was not intended to and therefore did not capture active-learning strategies specifically related to rural health. The varying specificity of the interventions described in the literature did not allow the researchers to assess curricular emphasis on rural vs urban social factors. However, additional research should also include an understanding of the regionality of social determinants of health. In US cities, the landscape of rural problems vs that for urban problems is quite different. ${ }^{44}$ For example, the time and expense required for someone in a small rural town to travel to get to work in the city vs the time and expense required for someone living in that city with access to properly operating public transportation to get to work. Programs may need to consider tailoring certain aspects of the curricula to the patient populations in areas where students will work for the students to gain a full appreciation for how the social determinants of health impact those populations. Schools might consider conducting a community needs assessment to determine where the majority of PharmD graduates plan to practice in order to determine the most relevant and applicable content for pharmacy students while still ensuring well-rounded exposure of all students to diverse populations.

Few professional students have truly been exposed to communities and challenges outside of their own lived experiences. The gap between what one knows the world to be and what the world actually is can only be narrowed through experience and exposure. For that reason, activelearning strategies regarding social determinants of health for health professions students is essential. Educators seeking to incorporate active learning in this area should consider the strategies to best meet the objectives of the 
American Journal of Pharmaceutical Education 2020; 84 (11) Article 8241.

Table 3. All Active Learning Strategies and SDOH Domains Covered

\begin{tabular}{|c|c|c|c|c|c|}
\hline Author & $\begin{array}{c}\text { Neighborhood and Built } \\
\text { Environment }\end{array}$ & $\begin{array}{l}\text { Health and } \\
\text { Healthcare }\end{array}$ & $\begin{array}{c}\text { Social and Community } \\
\text { Context }\end{array}$ & Education & $\begin{array}{c}\text { Economic } \\
\text { Stability }\end{array}$ \\
\hline Arif $(2017)^{23}$ & & - & - & - & \\
\hline $\begin{array}{l}\text { Baverstock } \\
(2018)^{24}\end{array}$ & • & • & & • & • \\
\hline $\begin{array}{l}\text { Clarke } \\
\qquad(2016)^{\mathrm{a}, 35}\end{array}$ & $\bullet$ & & & & $\bullet$ \\
\hline $\begin{array}{l}\text { Devraj } \\
\qquad(2010)^{\mathrm{a}, 26}\end{array}$ & & $\bullet$ & $\bullet$ & $\bullet$ & \\
\hline Haack $(2012)^{27}$ & & $\bullet$ & $\bullet$ & & $\bullet$ \\
\hline $\begin{array}{l}\text { Okoro } \\
\qquad(2015)^{\mathrm{a}, 36}\end{array}$ & • & • & • & & • \\
\hline Poirier $(2009)^{30}$ & & - & - & & \\
\hline $\begin{array}{l}\text { Prescott } \\
\qquad(2019)^{\mathrm{a}, 31}\end{array}$ & $\bullet$ & $\bullet$ & $\bullet$ & $\bullet$ & $\bullet$ \\
\hline Sales $(2013)^{\mathrm{a}, 37}$ & $\bullet$ & $\bullet$ & $\bullet$ & $\bullet$ & $\bullet$ \\
\hline Vyas $(2010)^{\mathrm{a}, 32}$ & - & $\bullet$ & $\bullet$ & $\bullet$ & $\bullet$ \\
\hline $\begin{array}{l}\text { Westberg } \\
\qquad(2005)^{\mathrm{a}, 33}\end{array}$ & • & • & $\bullet$ & • & $\bullet$ \\
\hline $\begin{array}{l}\text { Wilby } \\
\qquad(2015)^{\mathrm{a}, 38}\end{array}$ & $\bullet$ & • & $\bullet$ & & \\
\hline
\end{tabular}

- Denotes inclusion of SDOH domain in activities described in study

${ }^{a}$ Denotes inclusion of simulation-based activity in study

activity. On one hand, if the objectives of the activity are to provide exposure to and exploration of concepts, strategies such as discussion and reflection should be used. Alternatively, if the objective is to demonstrate skills (ie, medication history) during patient interactions, then a standardized patient should be considered because it gives students the opportunity to listen to the standardized patient's portrayed story, assess the information collected, and develop a plan of care. ${ }^{45}$ Standardized patients can also be used to assess pharmacy students' communication and counseling skills. In one study that compared a peer role-play exercise with the use of standardized patients showed that students scored higher in an assessment of communication skills when counseling a standardized patient than during peer role-play or other activities. ${ }^{46}$ Of the simulation strategies assessed in this review, only one study described the incorporation of standardized patients. This highlights the need for educators to include standardized patients in simulations to increase the authenticity and applicability of learning experiences.
There are several limitations to this review. First, the nature of a scoping methodology implies less specificity than do other styles of review, which can be a limitation by design. Rather than a review that screens studies based on the quality of the evidence, a scoping review focuses on determining the breadth of existing literature on a topic. Thus, appraisal of the validity of the assessments used and active-learning strategies employed in the studies was not undertaken. Second, publication bias is another limitation associated with reviews as nonsignificant and negative study results are often not submitted for publication. Although this scoping review captured a wide variety of active-learning strategies to teach $\mathrm{SDOH}$, some relevant activities may not have been captured as educational abstracts and presentations were not included in the search. Neither were activities captured that had been developed to teach social determinants of health but had not been published in the literature at the time the review was conducted. Finally, this review was conducted in the fall of 2019. Literature published more recently may not have been included in the search. 


\section{American Journal of Pharmaceutical Education 2020; 84 (11) Article 8241.}

The reviewed literature varied in type of activities used and domains incorporated for $\mathrm{SDOH}$, as well as in study designs and outcomes. Additionally, some of the available literature may not thoroughly describe the activity used to teach $\mathrm{SDOH}$, which posed a challenge when attempting to classify an activity as using simulation vs non-simulation-based active learning.

\section{CONCLUSION}

Although the pharmacist's role in addressing the social determinants of health has not been well defined, the published literature suggests that schools and colleges of pharmacy appear to not consistently integrate all five components of SDOH equally into active-learning curricula. The results of this study also suggest that simulation-based education is not currently being used to its full potential to teach student pharmacists the role SDOH can play on a patient's health. While it may be unreasonable to expect that each active-learning activity will be designed to equally encompass all five SDOH concepts, colleges of pharmacy must purposefully include a thorough examination of all domains in their curricula. The interplay between the concepts of cultural competency and SDOH is complex and multidimensional, and not all cultural competency activities sufficiently cover SDOH concepts. The sparsity of literature on SDOH and the lack of variety in the types of simulated experiences and assessments that have been reported reveal gaps and opportunities or innovation in terms of future research.

\section{ACKNOWLEDGMENTS}

The authors would like to acknowledge Nancy BorjaHart, PharmD, for reviewing this article.

\section{REFERENCES}

1. Sisko AM, Keehan SP, Poisal JA, et al. National health expenditure projections, 2018-27: economic and demographic trends drive spending and enrollment growth. Health Aff (Millwood). 2019; 38(3):491-501. doi:10.1377/hlthaff.2018.05499

2. Centers for Medicare and Medicaid Services. National Health Expenditure Data - Historical. https://www.cms.gov/ResearchStatistics-Data-and-Systems/Statistics-Trends-and-Reports/ NationalHealthExpendData/NationalHealthAccountsHistorical. Accessed November 2019.

3. Papanicolas I, Woskie LR, Jha AK. Health care spending in the United States and other high-income countries [published correction appears in JAMA. 2018 May 1;319(17):1824]. JAMA. 2018;319(10): 1024-1039. doi:10.1001/jama.2018.1150

4. Life Expectancy in America has Declined for Two Years in a Row. https://www.economist.com/united-states/2018/01/04/lifeexpectancy-in-america-has-declined-for-two-years-in-a-row. Accessed November 2019.

5. County Health Rankings Model. County Health Rankings \& Roadmaps. https://www.countyhealthrankings.org/explore-health- rankings/measures-data-sources/county-health-rankings-model. Accessed November 2019.

6. World Health Organization. About social determinants of health. https://www.who.int/social_determinants/sdh_definition/en/. Accessed November 2019.

7. Healthy People 2020. Social Determinants of Health. https:// www.healthypeople.gov/2020/topics-objectives/topic/socialdeterminants-of-health. Accessed November 2019.

8. Thorton M. Preparing today's nurses: social determinants of health and nursing education. The Online Journal of Issues in Nursing. 2018;23(3). doi: 10.3912/OJIN.Vol23No03Man05

9. Westerhaus M, Finnegan A, Haidar M, Kleinman A, Mukherjee J, Farmer P. The necessity of social medicine in medical education. Acad Med. 2015;90(5):565-568. doi:10.1097/ ACM.0000000000000571

10. Kumagai AK, Lypson ML. Beyond cultural competence: critical consciousness, social justice, and multicultural education. Acad Med. 2009;84(6):782-787. doi:10.1097/ACM.0b013e3181a42398 11. Ross PT, Wiley Cené C, Bussey-Jones J, et al. A strategy for improving health disparities education in medicine. J Gen Intern Med. 2010;25 Suppl 2(Suppl 2):S160-S163. doi:10.1007/s11606-0101283-3

12. Neff J, Holmes SM, Knight KR, et al. Structural competency: curriculum for medical students, residents, and interprofessional teams on the structural factors that produce health disparities. MedEdPORTAL. 2020;16:10888. doi: 10.15766/mep_23748265.10888

13. NLN releases a vision for integration of the social determinants of health into nursing education curricula. Nurs Educ Perspect. 2019; 40(6):390. doi:10.1097/01.NEP.0000000000000597

14. Medina MS, Plaza CM, Stowe CD, et al. Center for the Advancement of Pharmacy Education 2013 educational outcomes. Am J Pharm Educ. 2013;77(8):162. doi:10.5688/ajpe 778162 15. American Council on Pharmacy Education. Accreditation Standards and Key Elements for the Professional Program in Pharmacy Leading to the Doctor of Pharmacy Degree. Published 2016. https://www.acpe-accredit.org/pdf/Standards2016FINAL.pdf. Accessed November 2019.

16. Blouin RA, Joyner PU, Pollack GM. Preparing for a renaissance in pharmacy education: the need, opportunity, and capacity for change. Am J Pharm Educ. 2008;72(2):42. doi:10.5688/aj720242 17. Poirier TI. Is lecturing obsolete? advocating for high value transformative lecturing. Am J Pharm Educ. 2017;81(5):83. doi: 10.5688/ajpe 81583

18. Society for Simulation in Healthcare. About Simulation. https:// www.ssih.org/About-SSH/About-Simulation. Accessed January 2020 .

19. Busebaia TJA, John B. Can flipped classroom enhance class engagement and academic performance among undergraduate pediatric nursing students? A mixed-methods study. RPTEL. 2020; 15(4). doi: 10.1186/s41039-020-0124-1.

20. Shah S, Tohmasi S, Frisch E, et al. A comparison of simulation versus didactics for teaching ultrasound to Swiss medical students. World J Emerg Med. 2019;10(3):169-176. doi:10.5847/wjem.j.19208642.2019.03.007

21. Maran NJ, Glavin RJ. Low- to high-fidelity simulation - a continuum of medical education. Med Educ. 2003;37 Suppl 1:22-28. doi:10.1046/j.1365-2923.37.s1.9.x

22. Arksey H, O’Malley L. Scoping studies: towards a methodological framework. Int J Soc Res Methodol. 2005;8(1):19-32. doi: 10.1080/1364557032000119616 


\section{American Journal of Pharmaceutical Education 2020; 84 (11) Article 8241.}

23. Arif S, Cryder B, Mazan J, Quiñones-Boex A, Cyganska A. Using patient case video vignettes to improve students' understanding of cross-cultural communication. Am J Pharm Educ. 2017;81(3):56. doi:10.5688/ajpe81356

24. Baverstock KA, Gargya DM, Jackson M, Stupans I. Identifying future health professionals' understanding of the determinants of health. $J$ Nurs Educ. 2018;57(12):756-759. doi:10.3928/01484834-20181119-10

25. Cailor SM, Chen AMH. Immediate and longitudinal effects of incorporating health literacy and cultural competency into a yearlong pharmacy curriculum. Curr Pharm Teach Learn. 2015;7(3):292-301. doi: $10.1016 /$ j.cptl.2014.12.005

26. Devraj R, Butler LM, Gupchup GV, Poirier TI. Active-learning strategies to develop health literacy knowledge and skills. Am J Pharm Educ. 2010;74(8):137. doi:10.5688/aj7408137

27. Haack S, Phillips C. Teaching cultural competency through a pharmacy skills and applications course series. Am J Pharm Educ. 2012;76(2):27. doi:10.5688/ajpe76227

28. Liu M, Poirier T, Butler L, Comrie R, Pailden J. Design and evaluation of interprofessional cross-cultural communication sessions. J Interprof Care. 2015;29(6):622-627. doi:10.3109/ 13561820.2015.1051215

29. Muzumdar JM, Holiday-Goodman M, Black C, Powers M. Cultural competence knowledge and confidence after classroom activities. Am J Pharm Educ. 2010;74(8):150. doi:10.5688/ aj7408150

30. Poirier TI, Butler LM, Devraj R, Gupchup GV, Santanello C, Lynch JC. A cultural competency course for pharmacy students. Am J Pharm Educ. 2009;73(5):81. doi:10.5688/aj730581

31. Prescott GM, Nobel A. A multimodal approach to teaching cultural competency in the doctor of pharmacy curriculum. Am J Pharm Educ. 2019;83(4):6651. doi:10.5688/ajpe6651

32. Vyas D, Caligiuri FJ. Reinforcing cultural competency concepts during introductory pharmacy practice experiences. Am J Pharm Educ. 2010;74(7):129. doi:10.5688/aj7407129

33. Westberg SM, Bumgardner MA, Lind PR. Enhancing cultural competency in a college of pharmacy curriculum. Am J Pharm Educ. 2005;69(5):82. doi: 10.5688/aj690582

34. Assemi M, Cullander C, Hudmon KS. Implementation and evaluation of cultural competency training for pharmacy students. Ann Pharmacother. 2004;38(5):781-786. doi:10.1345/aph.1D402 35. Clarke C, Sedlacek RK, Watson SB. Impact of a simulation exercise on pharmacy student attitude toward poverty. Am J Pharm Educ. 2016;80(2):21. doi:10.5688/ajpe80221
36. Okoro O, Odedina F, Smith WT. Determining the sufficiency of cultural competence instruction in pharmacy school curriculum. Am J Pharm Educ. 2015;79(4):50. doi:10.5688/ajpe79450

37. Sales I, Jonkman L, Connor S, Hall D. A comparison of educational interventions to enhance cultural competency in pharmacy students. Am J Pharm Educ. 2013;77(4):76. doi:10.5688/ ajpe 77476

38. Wilby KJ, Taylor J, Khalifa SI, Jorgenson D. A course-based cross-cultural interaction among pharmacy students in Qatar and Canada. Am J Pharm Educ. 2015;79(2):26. doi:10.5688/ ajpe 79226

39. Smith LS. Concept analysis: cultural competence. J Cult Divers. 1998;5(1):4-10.

40. Accreditation Council for Pharmacy Education. Standards 2007. https:// www.acpe-accredit.org/pdf/S2007Guidelines2.0_ChangesIdentifiedInRed. pdf. Accessed November 2019.

41. Centers for Disease Control and Prevention. The SocialEcological Model: A Framework for Prevention. https:// www.cdc.gov/violenceprevention/publichealthissue/socialecologicalmodel.html\#: : :text $=$ Prevention $\% 20$ requires $\%$ 20understanding $\% 20$ the $\% 20$ factors, $\% 2$ C $\% 20$ community $\% 2 \mathrm{C} \%$ 20 and $\% 20$ societal\%20factors. Accessed July 2020.

42. Diaz-Cruz ES. If cultural sensitivity is not enough to reduce health disparities, what will pharmacy education do next? Curr Pharm Teach Learn. 2019;11(5):538-540. doi:10.1016/ j.cptl.2019.02.003

43. Daniel H, Bornstein SS, Kane GC. Health and Public Policy Committee of the American College of Physicians. Addressing social determinants to improve patient care and promote health equity: an American College of Physicians position paper. Ann Intern Med. 2018;168(8):577-578. doi:10.7326/M17-2441

44. National Advisory Committee on Rural Health and Human Services Policy Brief, January 2017. Social Determinants of Health. https://www.hrsa.gov/sites/default/files/hrsa/advisory-committees/ rural/publications/2017-social-determinants.pdf. Accessed January 2020.

45. Schweickerdt-Alker L. Revitalizing the SP through authentication: the authentic portrayal. Medical Teacher. 2014;36: 541-543. doi: 10.3109/0142159X.2014.887832.

46. Gillette C, Rudolph M, Rockich-Winston N, Stanton R, Anderson HG Jr. Improving pharmacy student communication outcomes using standardized patients. Am J Pharm Educ. 2017;81(6): 110. doi:10.5688/ajpe 816110 